\title{
Nondopaminergic Prefrontocortical Efferent Fibers Modulate D1 Receptor Denervation Supersensitivity in Specific Regions of the Rat Striatum
}

\author{
D. Herve, F. Trovero, G. Blanc, A. M. Thierry, J. Glowinski, and J. P. Tassin \\ Laboratoire de Neuropharmacologie, INSERM U.114, Collège de France, 75231 Paris Cedex 05, France
}

A unilateral injection of 6-OHDA $(6 \mu \mathrm{g} / 1.5 \mu \mathrm{l})$ was made into the fields of Forel in order to estimate the effects of the destruction of ascending dopaminergic (DA) pathways on the denervation supersensitivity of DA D1 receptors in the rat striatum. DA-sensitive adenylate cyclase activity was markedly enhanced in the anteromedian part of the striatum 3 weeks after the lesion ( $+68 \%$ ) and remained elevated for several weeks thereafter $(+36 \%)$. A different response occurred in the laterodorsal striatum, where the increase in DA-sensitive adenylate cyclase activity was less pronounced after 3 weeks $(+40 \%)$ and no longer present after 7 weeks. Estimations of catecholamine levels indicated that the lesion made destroyed not only nigrostriatal DA neurons but other ascending catecholaminergic fibers projecting into the cerebral cortex as well. In addition, retrograde transport experiments made with wheat germ agglutinin coupled to horseradish peroxidase indicated that the anteromedian part of the striatum, but not the laterodorsal one, receives both an ipsi- and contralateral cortical projection originating in the prefrontocortical DA field. When the destruction by 6-OHDA of this contralateral DA innervation was combined to the unilateral lesion of the fields of Forel, the increase in DA-sensitive adenylate cyclase activity in each striatal area 3 or 7 weeks postlesion was prevented. This effect was due to DA denervation of the prefrontal cortex since striatal D1 denervation supersensitivity was still observed when contralateral ascending noradrenergic fibers were selectively destroyed by a 6-OHDA lesion made laterally to the pedunculus cerebellaris superior. These results suggest that, by controlling the activity of corticostriatal neurons, the mesocorticoprefrontal DA neurons exert a permissive role on the development of D1-receptor denervation supersensitivity in specific areas of the striatum.

In the CNS, dopaminergic (DA) neurotransmission is mediated through 2 main types of DA postsynaptic receptors: The larger population of these receptors, termed D1, is positively coupled to adenylate cyclase (Kebabian et al., 1972; Boyson et al., 1986). The other reccptor population, called D2, is either negatively coupled to adenylate cyclase or linked to phospholipase $\mathrm{C}$ or a

\footnotetext{
Received Sept. 20, 1988; revised Jan. 26, 1989; accepted Mar. 3, 1989.

We wish to thank Dr. P. Vezina for his help in preparing this paper. This study was supported by INSERM and grants from Rhône Poulenc Santé.

Correspondence should be addressed to Denis Herve, Laboratoire de Neuropharmacologie, INSERM U. 114, Collège de France, 11 Place Marcelin Berthelot, 75231 Paris Cedex 05, France.

Copyright $\odot 1989$ Society for Neuroscience $0270-6474 / 89 / 113699-10 \$ 02.00 / 0$
}

potassium channel (Onali et al., 1985; Enjalbert et al., 1986; Freedman and Weight, 1988).

Several groups have attempted to demonstrate a denervationinduced increase in DA-sensitive adenylate cyclase activity in the striatum following destruction of the nigrostriatal DA pathway (Von Voigtlander et al., 1973; Mishra et al., 1974; Krueger et al., 1976). Contradictory results were obtained and the differences observed varied in their amplitude. It has also been reported that the density of D1 receptors, as estimated with labeled SCH 23390, a specific antagonist of D1 receptors, is not affected following denervation of the nigrostriatal DA pathway measured either by binding techniques (Langer et al., 1986) or by quantitative autoradiography (Beresford et al., 1988; Savasta et al., 1988). These results might indicate either that the supersensitivity of DA receptors, which is easily demonstrated in behavioral studies (Ungerstedt, 1971), is related only to modifications of D2 receptors or that D1-receptor supersensitivity is not linked to an increase in the number of D1 receptors but to a change in DA-sensitive adenylate cyclase activity, i.e., to an increased number of D1 receptors coupled to adenylate cyclase. Indeed, it was recently shown that the striatum contains a large proportion of "spare D1 receptors" not coupled to adenylate cyclase (Hess et al., 1987).

The variable results obtained when changes in DA-adenylate cyclase activity are measured following striatal DA denervation could be attributed to differences in the nature (chemical or electrolytic), the size, and the localization of the lesions. For example, electrolytic lesions destroy non-DA neurons as well as ascending DA neurons, and 6-OHDA lesions may destroy not only nigrostriatal DA neurons but also other ascending catecholaminergic pathways. Such nonselective lesions could modify the activity of non-DA neurons projecting onto the target cells of nigrostriatal DA neurons and consequently alter the coupling of D1 receptors to adenylate cyclase. Indeed, it has been shown that the increase in DA-sensitive adenylate cyclase activity does not occur systematically following the destruction of DA afferent fibers in the prefrontal cortex and the nucleus accumbens. Non-DA systems could modulate the development of this denervation receptor supersensitivity through heterologous interactions. Noradrenergic (NA) afferent fibers and possibly glutamatergic cortical efferent neurons seem to play major roles in such a heteroregulation of D1 receptor responsiveness in the prefrontal cortex and the nucleus accumbens, respectively (Tassin et al., 1982, 1986; Reibaud et al., 1984).

In order to test this hypothesis, unilateral 6-OHDA injections were made into the fields of Forel, a site through which courses all ipsilateral DA ascending fibers (including those innervating 


\section{ANTERO-MEDIAN STRIATUM}

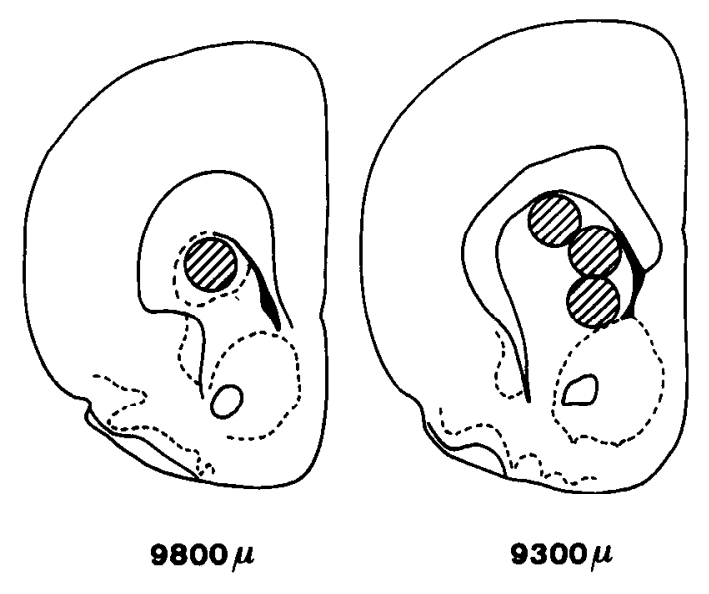

\section{LATERO-DORSAL STRIATUM}

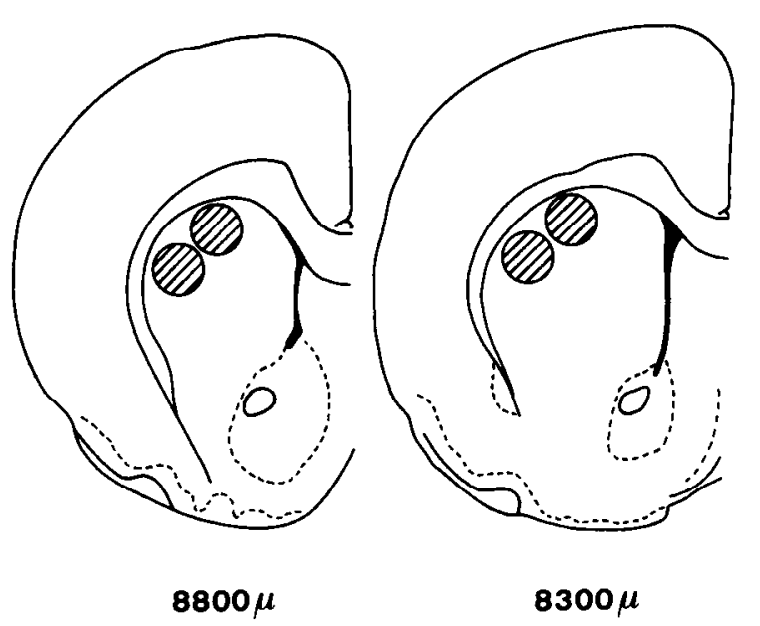

Figure 1. Localization of the microdisks of striatal tissue punched out to measure DA-sensitive adenylate cyclase activity and DA levels. Microdisks ( $0.9 \mathrm{~mm}$ diameter) containing $32 \mu \mathrm{g}$ protein each were punched out from $500-\mu \mathrm{m}$-thick frontal slices. Four microdisks punched out from each of the anteromedian and laterodorsal parts of the striatum were pooled for biochemical assays. Drawings are taken from the atlas of König and Klippel (1963).

the prefrontal cortex). Seven weeks later, it was found that modifications in DA-stimulated adenylate cyclase activity were not homogeneous throughout the striatum. In some regions, large increases were observed, while in others no changes could be detected. Since an anatomical analysis indicated that the regions in which DA-stimulated adenylate cyclase activity was increased received a major contingent of fibers originating from both the ipsi- and the contralateral prefrontal cortex, the role of these latter cortical neurons was investigated. In this article, we demonstrate that the integrity of the DA innervation of the contralateral prefrontal cortex is necessary for the development of long-term D1-receptor denervation supersensitivity in the striatum. Since DA released in the prefrontal cortex directly or indirectly controls the activity of cortical efferent neurons (Ferron et al., 1984; Thierry et al., 1984), this suggests that non-DA prefrontocorticostriatal neurons participate in the modulation of D1-receptor sensitivity in the striatum.

\section{Materials and Methods}

Animals

Male Sprague-Dawley rats (250-300 gm, Charles River, France) were used. These were group-housed in a $12 \mathrm{hr}$ dark-light cycle room with temperature maintained at $22^{\circ} \mathrm{C}$ and $60 \%$ humidity.

\section{Lesions}

Animals were lesioned under ketamine anesthesia (Imalgene $\mathrm{R}$, Iffamérieux, $150 \mathrm{mg} / \mathrm{kg}$, i.p.) using a David Kopf stereotaxic apparatus (DK 900). The incisor bar was placed $3.4 \mathrm{~mm}$ above the interaural line.

6-OHDA microinjections made into the fields of Forel. A microinjection cannula was implanted into the left fields of Forel at the following coordinates: $2.2 \mathrm{~mm}$ caudal to Bregma, $1.6 \mathrm{~mm}$ lateral to the midline, and $8.4 \mathrm{~mm}$ under the surface of the skull. 6-OHDA was dissolved in a solvent containing $\mathrm{NaCl}$ ( $9 \mathrm{gm} /$ liter) and ascorbic acid ( $0.2 \mathrm{gm} / \mathrm{liter})$, adjusted to $\mathrm{pH} 4.3$, and injected at a dose of $6 \mu \mathrm{g}$ in a volume of 1.5 $\mu 1$ over $5 \mathrm{~min}$.

6-OHDA microinjections made into the prefrontal cortex. The catecholamine innervation of the prefrontal cortex was specifically destroyed by microinjection of 6-OHDA ( $8 \mu \mathrm{g}$ in $2 \mu \mathrm{l}$ of the previously described solvent), $3.5 \mathrm{~mm}$ rostral to the Bregma, $0.5 \mathrm{~mm}$ lateral to the midline, and $4.9 \mathrm{~mm}$ under the skull surface.

6-OHDA microinjections made laterally to the pedunculus cerebellaris superior. The NA innervation of the prefrontal cortex was destroyed by microinjection of $6-O H D A(6 \mu \mathrm{g} / 1.5 \mu \mathrm{l}$ solvent) $6.0 \mathrm{~mm}$ caudal to the Bregma, $1.4 \mathrm{~mm}$ lateral to the midline, and $7.5 \mathrm{~mm}$ under the skull surface.

\section{Retrograde labeling of corticostriatal neurons}

Rats anesthetized with ketamine $(150 \mathrm{mg} / \mathrm{kg}$, i.p.) received 2 injections of wheat germ agglutinin horseradish peroxidase (WGA-HRP, Sigma) in 2 different regions of the striatum (Fig. 1). The first injection was located into the anteromedian part of the striatum (anteriority, 9650 $\mu \mathrm{m}$; laterality, $2 \mathrm{~mm} ; 3.95 \mathrm{~mm}$ from dura), according to the atlas of König and Klippel (1963). The second injection was made into the laterodorsal part of the striatum (anteriority, $8600 \mu \mathrm{m}$; laterality, 3.1 $\mathrm{mm} ; 3.7 \mathrm{~mm}$ from dura).

In both cases, a glass micro-pipette ( $10 \mathrm{M} \Omega$ impedance) containing WGA-HRP (4\%) dissolved in isotonic saline solution ( $\mathrm{pH} 7.5$ ) was implanted unilaterally into the left striatum. WGA-HRP was applied iontophoretically using 7 30-sec-long pulses of positive current each separated by $90 \mathrm{sec}$.

Forty-eight hours later, the animals were anesthetized again with ketamine and perfused through the aortic arch sequentially with 150 $\mathrm{ml}$ of $0.9 \% \mathrm{NaCl}$, with $300 \mathrm{ml}$ of $0.1 \mathrm{M}$ phosphate buffer ( $\mathrm{pH} \mathrm{7.4)}$ containing $4 \%$ glutaraldehyde and finally with the same phosphate buffer solution containing $10 \%$ sucrose. Brains were dissected out and rinsed overnight with phosphate sucrose buffer. Brains were then frozen in isopentane maintained at $-40^{\circ} \mathrm{C}$ and $50-\mu \mathrm{m}$-thick sections were collected in phosphate buffer using a freezing microtome (Leitz-Wetzlar). WGA-HRP labeling was revealed according to the procedure of Mesulam (1978) using the tetramethylbenzidine reaction. Sections were mounted onto gelatin-coated slides, quickly dehydrated in graded ethanol, defatted in xylene, and coverslipped. Finally, the pattern of labeled cortical cells was reconstructed from photomontages of frontal sections.

\section{Biochemical methods}

Tissue sampling. Lesioned and control animals were killed by decapitation. Brains were rapidly dissected out and their anterior half frozen at $-7^{\circ} \mathrm{C}$ on a Leitz-Wetzlar microtome stage refrigerated by a Leitz Kryomat. Serial brain sections ( $500 \mu \mathrm{m}$ thick) were cut and placed onto the refrigerated stage.

Two equilateral triangular punches (each containing $0.36 \mathrm{mg}$ protein) were taken bilaterally from the prefrontal cortex (Lavielle et al., 1979) and immersed into $110 \mu \mathrm{l}$ of a perchloric acid solution $(0.1 N)$ containing sodium metabisulfite $(0.05 \%)$.

Four circular microdisks of tissue $(0.9 \mathrm{~mm}$ diameter, $32 \mu \mathrm{g}$ protein each) were dissected from the anteromedian, laterodorsal (Fig. 1), ventromedial, and central parts of the striatum at the 9800 and 9300,8800 and 8300,7800 and 7300 , and 7800 and $7300 \mu \mathrm{m}$ planes, respectively, according to the atlas of König and Klippel (1963). The 4 microdisks dissected out from each region were pooled.

Adenylate cyclase assay. Microdisks were homogenized in $175 \mu \mathrm{l}$ of 


\section{ANTERO-MEDIAN STRIATUM}
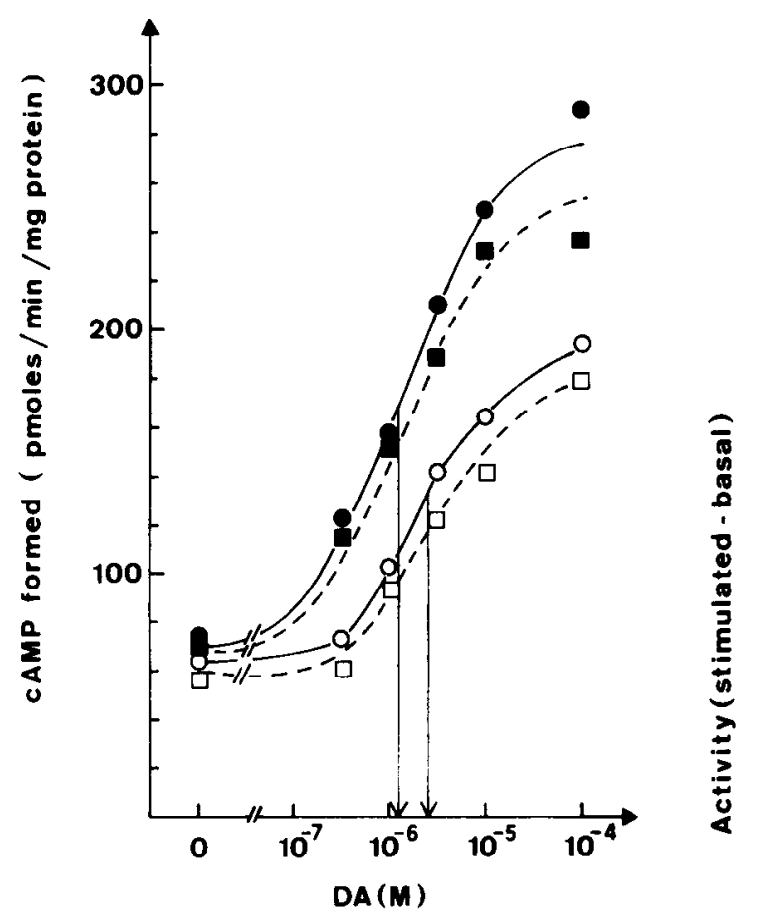
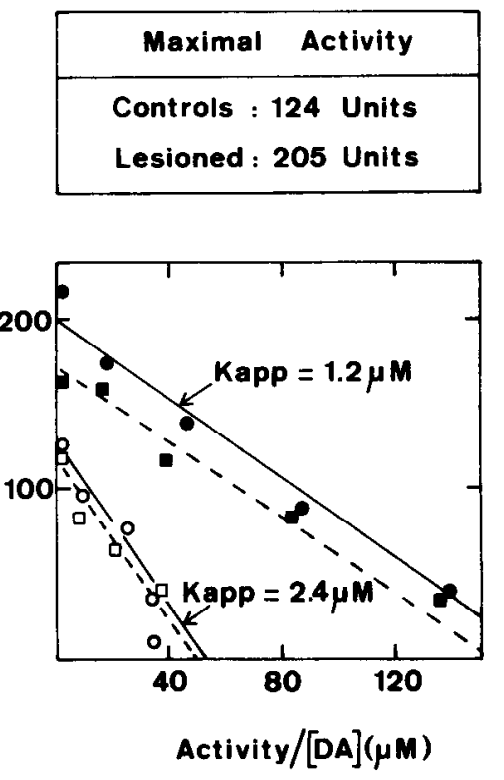

\section{LATERO-DORSAL STRIATUM}

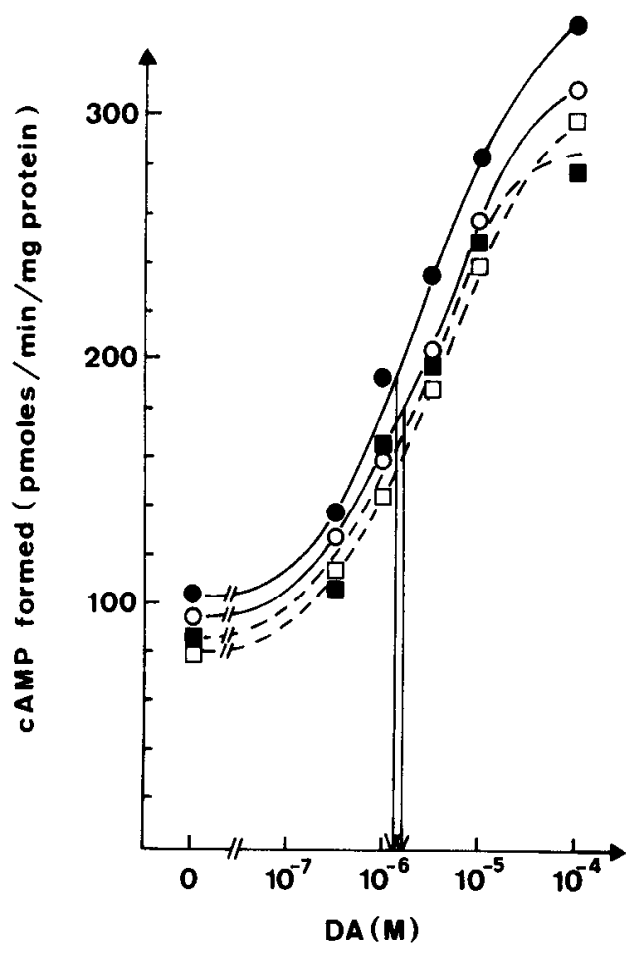

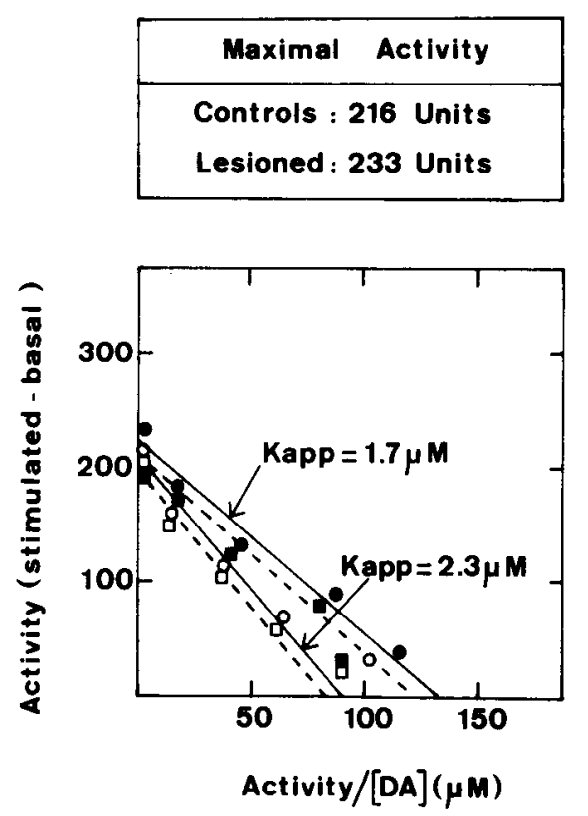

Figure 2. Dose-response curves of the $\mathrm{DA}$-sensitive adenylate cyclase activity in the presence or absence of added GTP in 2 striatal areas following a 6-OHDA injection into the fields of Forel. Seven weeks following the lesion, tissues from 2 control (open symbols) and 2 lesioned (filled symbols) animals were pooled and DA-sensitive adenylate cyclase activity measured for various concentrations of DA in the presence (squares) or absence (circles) of $1 \mu \mathrm{m}$ added GTP. Each point corresponds to the mean value of $2 \mathrm{de}$ terminations that did not differ by more than $8 \%$. One unit represents 1 pmol/ $\mathrm{min} / \mathrm{mg}$ protein of cAMP formed.
$2 \mathrm{~mm}$ Tris-maleate (pH 7.2) containing $2 \mathrm{mM}$ EGTA and $300 \mathrm{~mm}$ sucrose using a Potter-Elvehjem apparatus (10 strokes). Adenylate cyclase activity was assayed by measuring the conversion of $\alpha^{-32} \mathrm{P}$-ATP into ${ }^{32} \mathrm{P}$-cyclic AMP in the absence or presence of various concentrations of DA (0.3-100 $\mu \mathrm{M}$ range) (Bockaert et al., 1977). The incubation medium (final volume, $40 \mu \mathrm{l})$ contained Tris-maleate $(25 \mathrm{~mm} ; \mathrm{pH} 7.2)$, ATP $(0.5 \mathrm{~mm}), \mathrm{MgSO}_{4}(1 \mathrm{~mm})$, papaverine $(0.1 \mathrm{~mm})$, creatine phosphate
(10 mM), creatine kinase (EC 2.7.3.2., $0.2 \mathrm{mg} / \mathrm{ml}$ ), and adenosine deaminase (EC 3.5.4.4., 0.4 U/ml). In some experiments, GTP $(1 \mu \mathrm{M})$ or sulpiride $(1 \mu \mathrm{M})$ were added to the incubation medium. The reaction was initiated by the addition of $10 \mu \mathrm{l}$ homogenates and was allowed to proceed for $7 \mathrm{~min}$ at $30^{\circ} \mathrm{C}$. It was stopped by the addition of $100 \mu \mathrm{l}$ of a solution containing $5 \mathrm{~mm}$ ATP, $5 \mathrm{~mm}$ cyclic AMP, $50 \mathrm{~mm}$ Tris- $\mathrm{HCl}$ (pH 7.4), and $1 \%$ sodium lauryl sulfate. ${ }^{32} \mathrm{P}$-cyclic AMP formed was 


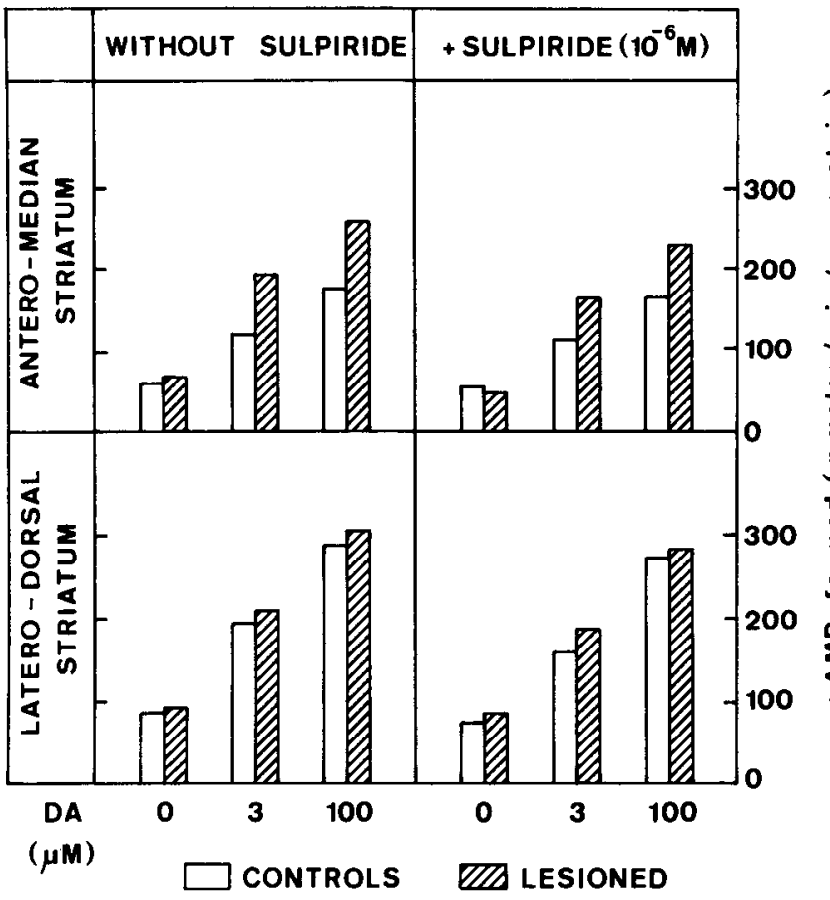

Figure 3. Effect of sulpiride on the DA-sensitive adenylate cyclase activity in 2 striatal areas following a 6-OHDA injection into the fields of Forel. Experimental conditions were identical to those described in the legend of Figure 2. No exogenous GTP was added.

separated according to Salomon et al. (1974). Adenylate cyclase activity was expressed in picomoles of cyclic AMP produced $/ \mathrm{min} / \mathrm{mg}$ protein.

Estimation of $D A$ and $N A$ levels. Aliquots $(30 \mu \mathrm{l})$ of striatal homogenates prepared for adenylate cyclase assay were poured into $50 \mu \mathrm{l}$ of $0.1 \mathrm{~N}$ perchloric acid containing $0.05 \%$ of sodium metabisulfite. Following centrifugation $(20,000 \times \mathrm{g}, 15 \mathrm{~min})$, fractions of supernatants $(8 \mu 1)$ were injected into a high-pressure liquid chromatography $\mathrm{C} 18$ column equilibrated with a solvent consisting of sodium phosphate buffer $(0.1 \mathrm{M}), 1$-octanesulfonic acid $(2.75 \mathrm{mM})$, triethylamine $(0.25 \mathrm{mM})$, EDTA $(0.1 \mathrm{~mm})$, methanol (15\%) adjusted with phosphoric acid to $\mathrm{pH}$ 2.9 (Wagner et al., 1982). Injection rate was $1 \mathrm{ml} / \mathrm{min}$. Levels of catecholamines were quantified by electrochemistry using a carbon electrode (Chromatofield Eldec 102) set at $0.65 \mathrm{~V}$. The peaks of NA and DA eluted at 5.4 and $12.6 \mathrm{~min}$, respectively. The data were analyzed with a peak integrator (Spectra Physics SP 4100). Only those animals with striatal DA levels decreased by more than $92 \%$ were kept for further analysis.

Prefrontal cortex. Tissue samples were ultrasonicated, centrifugated $(20,000 \times g, 15 \mathrm{~min})$, and the catecholamines purified on alumina microcolumns (Gauchy et al., 1976). Eluates were then lyophilized, dissolved in $60 \mu \mathrm{l}$ of water, and injected into a high-pressure liquid chromatography column. The remaining steps were identical to those performed for the quantification of catecholamines in striatal samples.

\section{Results}

Effects of unilateral injection of 6-OHDA into the fields of

Forel on DA-sensitive adenylate cyclase activity in

different areas of the ipsilateral striatum

Seven weeks following injection of 6-OHDA into the left fields of Forel, DA-sensitive adenylate cyclase activity was estimated in the anteromedian, laterodorsal, ventromedial, and central parts of the striatum. Interestingly, although DA levels were always $8 \%$ lower than control values in the different striatal areas, DA-sensitive adenylate cyclase activity measured with a saturating concentration of DA was not increased significantly

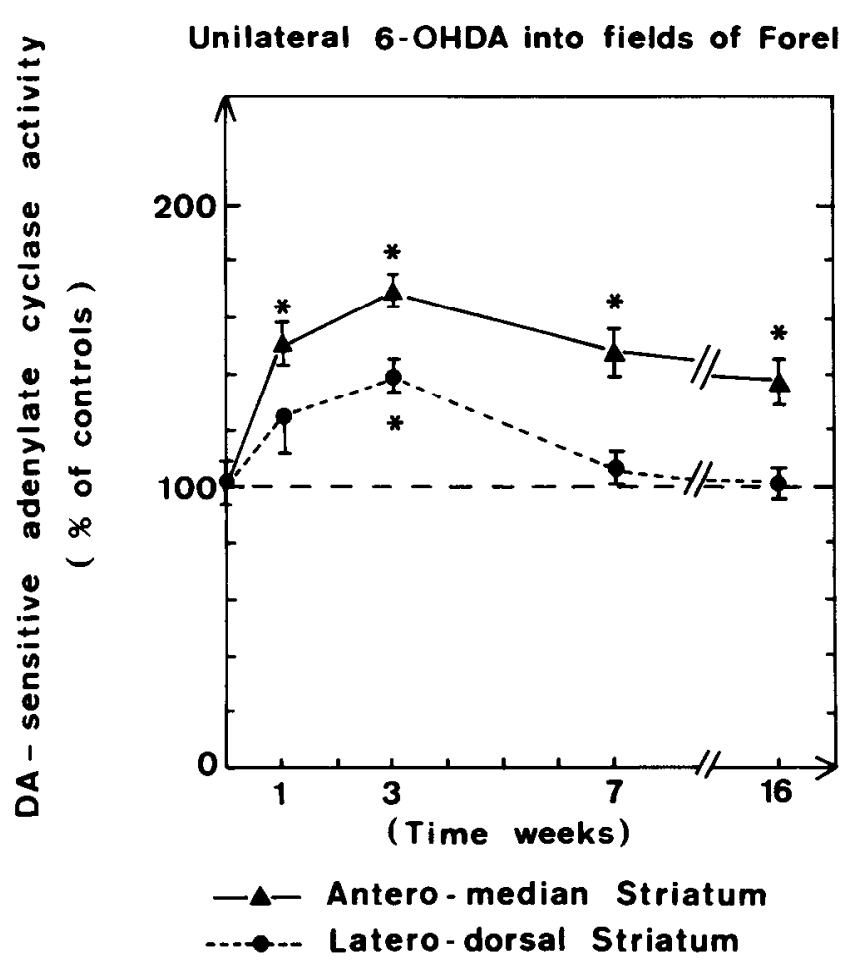

Figure 4. Time course of DA-sensitive adenylate cyclase activity in anteromedian and laterodorsal parts of the striatum following unilateral 6-OHDA injection into the fields of Forel. Mean basal and DA-stimulated adenylate cyclase activities for control animals were $102 \pm 8$ and $134 \pm 10 \mathrm{pmol} / \mathrm{min} / \mathrm{mg}$ protein (without DA) and $279 \pm 25$ and 341 $\pm 30 \mathrm{pmol} / \mathrm{min} / \mathrm{mg}$ protein (in the presence of $10^{-4} \mathrm{M} \mathrm{DA}$ ), respectively, for the anteromedian and laterodorsal parts of the striatum. DA-sensitive adenylate cyclase activity was determined in triplicates and calculated as the difference between DA-stimulated and baseline activity. Results are expressed as percentages of mean values obtained in corresponding control tissue homogenates. Each point is the mean $\pm \mathrm{SEM}$ obtained with groups of 4-6 rats. * $p<0.01$ (Student's $t$ test) compared with the respective control values.

in either the laterodorsal (Figs. 2-4) or central parts of the striatum. However, DA-sensitive adenylate cyclase activity was enhanced significantly in both the anteromedian (Figs. 2-4) and ventromedian $(+30 \%)$ parts of the striatum. Since factors such as changes in GTP concentrations or modifications of D2 receptors following DA denervation could be responsible for these differences, these were investigated by using the anteromedian and laterodorsal parts of the striatum as reference areas.

Stimulation of adenylate cyclase activity by various concentrations of DA in anteromedian and laterodorsal parts of control and DA-denervated striata

Figure 2 shows that the enhanced DA-sensitive adenylate cyclase activity obtained following DA denervation in the anteromcdian part of the striatum was associated with a 2-fold increase in the apparent affinity of DA for the D1 receptor adenylate cyclase complex. Although no significant change on DA-sensitive adenylate cyclase maximal activity could be detected in the denervated laterodorsal part of the striatum, a slight increase in the affinity of DA for the D1-receptor complex was observed in this striatal area (Fig. 2). This was likely due to the presence of an endogenous concentration of DA (approximately $0.4 \mu \mathrm{M}$ in the final volume) in the control homogenates. 
Effect of GTP on DA-sensitive adenylate cyclase activity following unilateral 6-OHDA injection into the fields of Forel

The amplitude of the effects induced by the 6-OHDA lesion was not significantly affected by the addition of GTP $(1 \mu \mathrm{M})$ to the assay (Fig. 2). In both lesioned and control animals, GTP did not modify the kinetic constants of DA-sensitive adenylate cyclase observed in the anteromedian and laterodorsal parts of the striatum (Fig. 2). Moreover, the weak decrease in basal and DA-stimulated adenylate cyclase activity indicates the presence of a saturating concentration of endogenous GTP in the tissue homogenates from both striatal subdivisions in the control (Prémont et al., 1979) as well as in lesioned animals.

Effect of sulpiride on DA-sensitive adenylate cyclase activity following unilateral 6-OHDA injection into the fields of Forel

The presence in the assay of sulpiride $(1 \mu \mathrm{M})$, a selective antagonist of D2 receptors, did not potentiate the stimulatory effect of 3 or $100 \mu \mathrm{M}$ DA on adenylate cyclase activity in the anteromedian and laterodorsal parts of the striatum (Fig. 3). This demonstrates that D2-receptor-mediated adenylate cyclase inhibition is negligible in our incubating conditions. Moreover, sulpiride did not significantly modify the effects produced by DA nigrostriatal lesions in either striatal subdivisions (Fig. 3).

Time course of DA-sensitive adenylate cyclase activity in the anteromedian and laterodorsal parts of the striatum following unilateral 6-OHDA injections into the fields of Forel

The time of death following the lesion may contribute to differences in the changes in DA-sensitive adenylate cyclase activity observed between different areas of the striatum. It is, indeed, possible that $\mathrm{D} 1$ receptors from only some striatal areas remain hypersensitive for a longer time following the destruction of the nigrostriatal DA pathway. This hypothesis was investigated in groups of 4 animals lesioned in the left fields of Forel killed 1, 3,7 , and 16 weeks following surgery. Each of these groups was paired with a group of control rats. All animals exhibited a marked reduction in DA levels in their left striatum superior to $92 \%$.

As shown in Figure 4, DA-sensitive adenylate cyclase activity was increased both in the anteromedian and the laterodorsal parts of the striatum as soon as $7 \mathrm{~d}$ following the lesion. This effect was maximal 3 weeks following DA denervation and then declined. The extent of the increase was always weaker in the laterodorsal (maximal increase, $+40 \%$ ) than in the anteromedian part (maximal increase, $+68 \%$ ) of the striatum. In addition, while DA-sensitive adenylate cyclase activity in the anteromedian part of the striatum remained significantly enhanced as long as 16 weeks following the lesion $(+36 \%)$, activity in the laterodorsal area had returned to control levels by 7 weeks postlesion (Fig. 4).

These data suggest that factors other than the time following the lesion contribute to the difference in the effect of DA denervation on the DA-sensitive adenylate cyclase activity observed between these 2 striatal areas.

Retrograde labeling of frontal cortex neurons following WGA-HRP injections into the anteromedian and laterodorsal parts of the striatum

Modifications in the activity of non-DA fibers projecting onto the target cells of the nigrostriatal DA neurons could influence the sensitivity of D1 receptors. Therefore, attempts were first made to determine the origin of the non-DA afferent fibers projecting into the 2 striatal reference areas. For this purpose, microiontophoretic injections of WGA-HRP were made into the anteromedian and laterodorsal parts of the striatum.

As revealed by peroxidase staining, the diameter of the diffusion zone at the injection site was $1.1 \mathrm{~mm}$, indicating that a possible overlap in the labeling of the 2 sites of injection was small.

Although several areas, such as the substantia nigra, contained peroxidase staining, the labeling in the anterior cortex was analyzed in detail since clear-cut differences were observed for the 2 sites of injection (Fig. 5).

Following injection of WGA-HRP into the anteromedian striatum, labeled cortical cells were found in all areas of the medial prefrontal cortex (Krettek and Price, 1977). Numerous positive cells were seen inside the boundaries of the DA cortical field as defined by Berger et al. (1976), Lindvall et al. (1978), and Björklund and Lindvall (1984). Moreover, comparably dense symmetrical labeling could be observed in the contralateral cortex (Fig. 5).

When WGA-HRP was injected into the laterodorsal striatum, labeled cortical cells were found to be, in general, more laterally localized than those labeled by the injection made into the anteromedian striatum. These cells were restricted predominantly to the lateral precentral area, but some were also seen in the medial precentral area and the somatosensory cortex. Interestingly, neurons labeled in the contralateral cortex were far less numerous than in the ipsilateral cortex. Moreover, the topography of these cells was slightly different since no labeled neurons could be found in the most lateral parts of the cortex. Finally and most importantly, almost all cells retrogradely labeled by WGA-HRP injections into the laterodorsal striatum were located outside the boundaries of the DA cortical field (Fig. $5)$.

These data provide 2 types of information (Fig. 6): First, a large population of the cortical neurons projecting to the anteromedian part of the striatum is located in the discrete cortical area that receives DA projections from the ventral tegmental area (VTA). This is not the case for the cortical cells innervating the laterodorsal part of the striatum. Second, the afferent fibers of the anteromedian part of the striatum originate both from the ipsilateral and contralateral cortices, while those innervating the laterodorsal part predominantly originate from the ipsilateral cortex.

Since the unilateral 6-OHDA injections made into the fields of Forel destroy not only the nigrostriatal DA system but also other ascending catecholaminergic fibers, including those innervating the cerebral cortex, this lesion could affect differentially the 2 main populations of cortical-subcortical neurons described above.

\section{Effects of combined 6-OHDA injections made into the left \\ fields of Forel and the right prefrontal cortex on the \\ $D A$-sensitive adenylate cyclase activity in the anteromedian striatum}

As shown in Table 1, a unilateral injection of 6-OHDA into the fields of Forel affected not only the levels of DA in the ipsilateral striatum but the DA and NA innervations in the ipsilateral prefrontal cortex as well. However, the catecholamine innervation of the contralateral prefrontal cortex was not significantly modified. This suggested that the preserved contralateral catecholaminergic innervation might be responsible for the pro- 


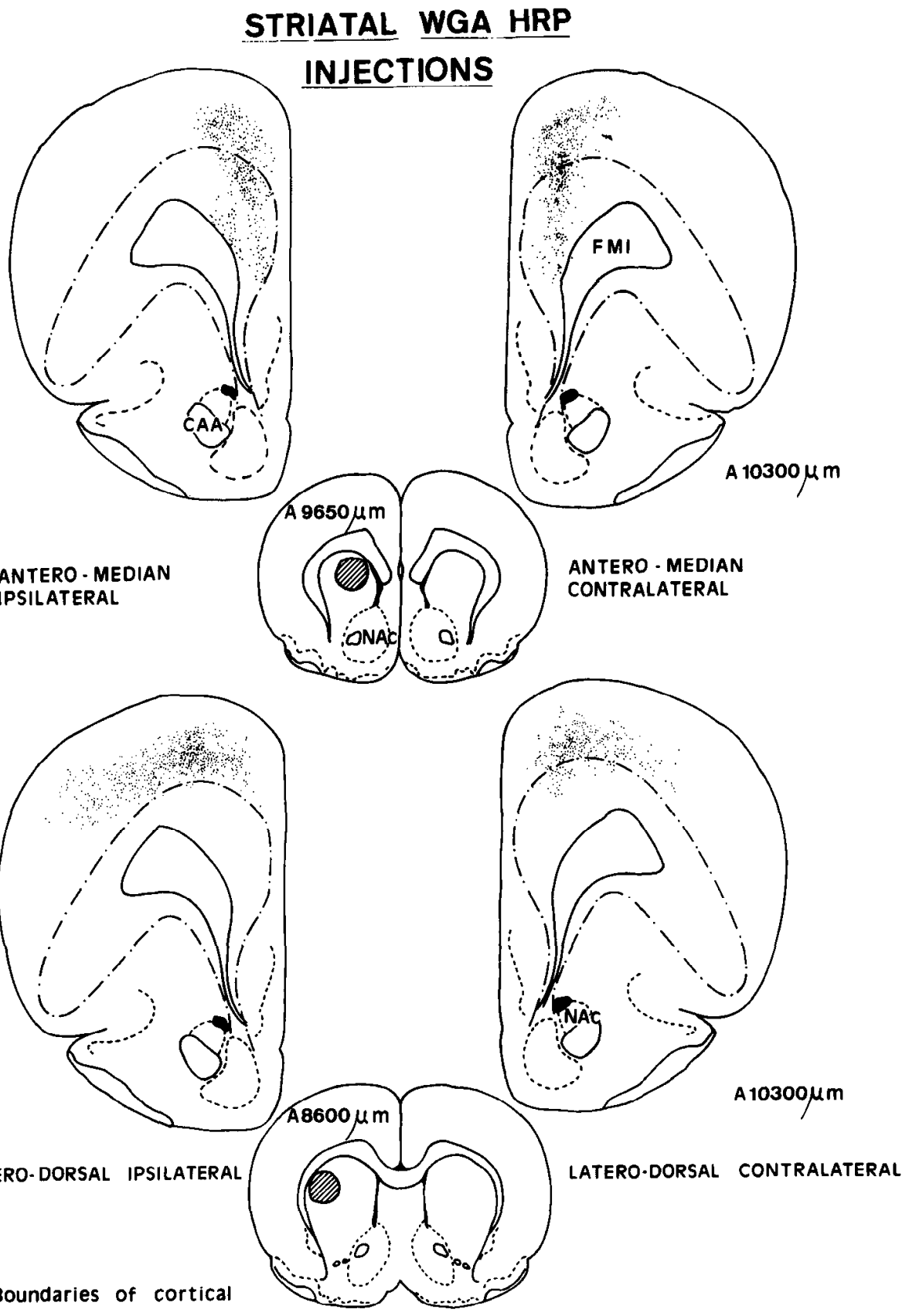

Figure 5. Reconstruction from photomontages of the distribution of labeled cortical cells following unilateral microiontophoretic injection of WGAHRP into the anteromedian or laterodorsal parts of the striatum. The hatched circles correspond to the zone of diffusion of the WGA-HRP. Each cortical dot represents a cell body labeled by retrograde transport of WGA-HRP. Note that there were almost no labeled cells in the DA cortical field (as defined by Berger et al., 1976, and Björklund and Lindvall, 1984) when WGA-HRP was injected into the laterodorsal part of the striatum. $C A A$, commissure anterior, pars anterior; $F M I$, forceps minor; $N A C$, nucleus accumbens. Drawings are from the atlas of König and Klippel (1963).

\section{$-\cdot-$ Boundaries of cortical}

dopaminergic (type I) fiela longed D1 receptor denervation hypersensitivity seen in the anteromedian part of the ipsilateral striatum. In order to test this hypothesis, DA-stimulated adenylate cyclase activity in the anteromedian part of the striatum was examined in rats that had received 6-OHDA injections both unilaterally in to the fields of Forel and in the contralateral prefrontal cortex. Animals were killed 3 or 7 weeks following surgery, and results were compared with those found in animals that had received only a unilateral 6-OHDA injection into the fields of Forel.

These combined lesions, as well as producing reductions in DA levels in the ipsilateral striatum, induced large decreases in DA and NA levels in both the right and left prefrontal cortices (Table 1). Three or 7 weeks after the combined 6-OHDA lesions, no significant modification in DA-sensitive adenylate cyclase activity was observed in the anteromedian part of the DAdenervated striatum, while, at the same time postlesion, the single unilateral injection of 6-OHDA into the fields of Forel continued to lead to a significant increase in DA-sensitive adenylate cyclase activity (Fig. 7).

The disappearance of $\mathrm{Dl}$ receptor denervation supersensitivity in the anteromedian striatum resulted from the bilateral destruction of the cortical DA but not NA innervation. Indeed, additional experiments indicated that a significant increase $(+38 \%, p<0.01)$ in DA-sensitive adenylate cyclase activity was still observed in the anteromedian part of the denervated striatum 7 weeks after 6-OHDA lesions were made both ipsilaterally to the fields of Forel and contralaterally to the pedunculus cerebellaris superior in order to specifically destroy the 


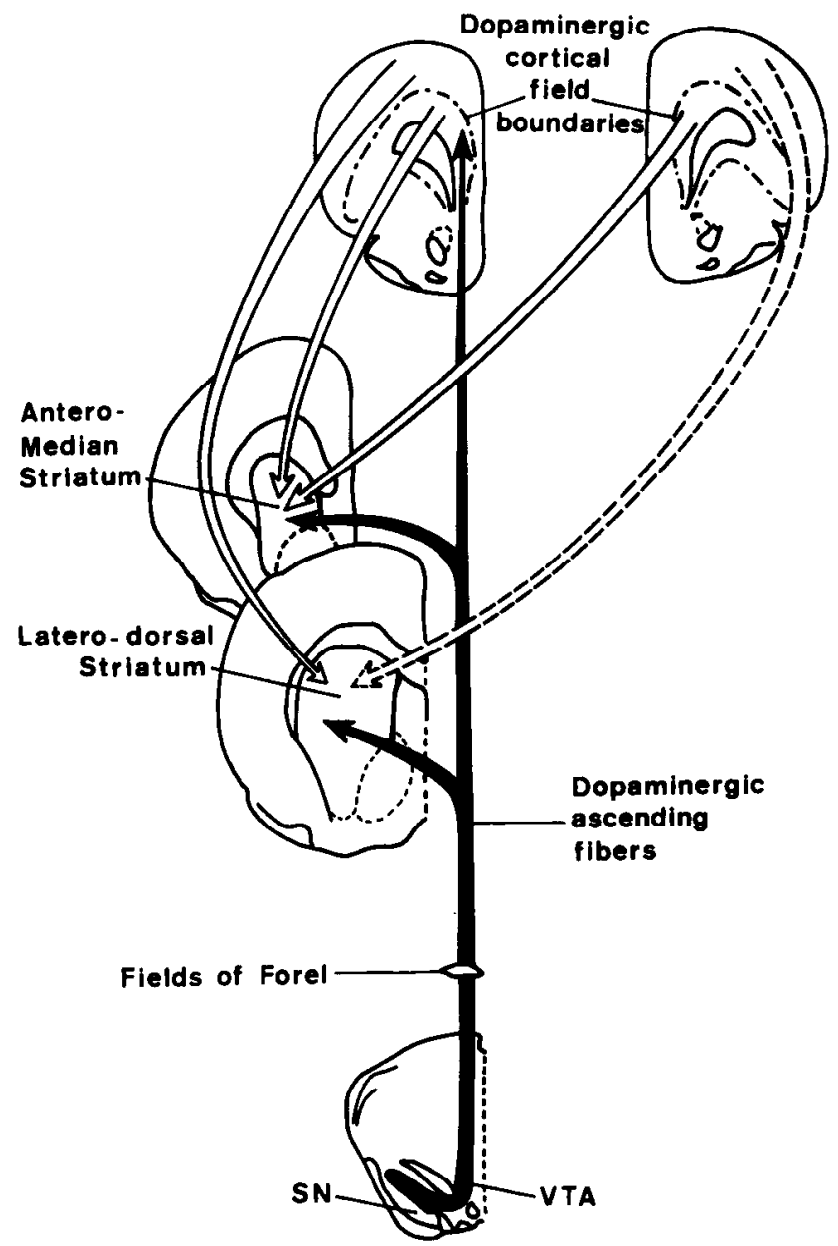

Figure 6. Schematic drawing of the anatomical relationships between ascending DA pathways and the anterior corticostriatal projections. Cortical cells located in the $\mathrm{D} \Lambda$ cortical field project bilaterally to the anteromedian striatum. The laterodorsal striatum receives cortical projections from cells lying predominantly outside the ipsilateral DA cortical field. In this latter case, the minor contralateral projections are also represented. $S N$, substantia nigra; $V T A$, ventral tegmental area.

ascending NA pathway. In these experiments, basal and DAstimulated adenylate cyclase activities were $87 \pm 7$ and $83 \pm$ $8 \mathrm{pmol} / \mathrm{min} / \mathrm{mg}$ of protein (without DA) and $230 \pm 9$ and 281 $\pm 12 \mathrm{pmol} / \mathrm{min} / \mathrm{mg}$ of protein (in the presence of $10^{-4} \mathrm{M} \mathrm{DA}$ ), respectively, for the control and the double-lesioned rats.

\section{Discussion}

\section{Methodological considerations}

In the present study, changes in the sensitivity of D1 receptors in striatal areas following destruction of ascending DA neurons were determined by measuring the stimulation of adenylate cyclase activity induced either by various or saturating concentrations $\left(10^{-4} \mathrm{M}\right)$ of DA. Sincc D2 receptors are coupled negatively to adenylate cyclase (Onali et al., 1985), it could be argued that DA acting on D2 receptors interferes with our estimation of D1 receptors coupled positively to adenylate cyclase. However, the D2-related inhibition of adenylate cyclase activity can be detected only in very specific conditions. For example, the presence of a high concentration (up to $5 \times 10^{-5} \mathrm{M}$ ) of GTP is required. This is likely due to the relatively low affinity of GTP for the Ni GTP-regulatory protein (Rodbell, 1980; Onali et al.,

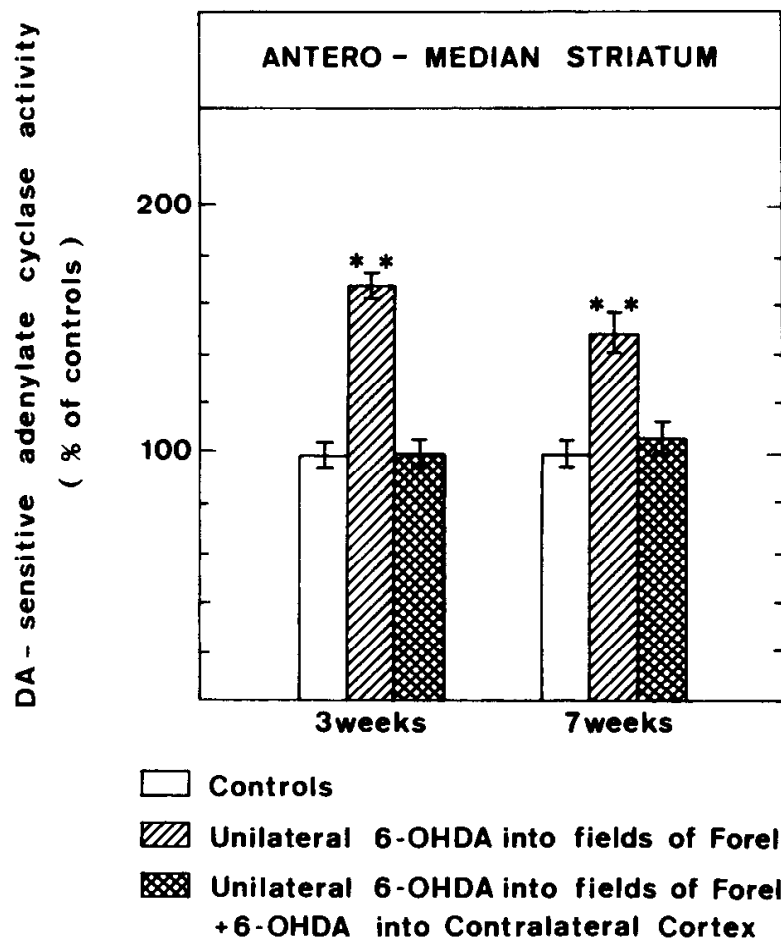

Figure 7. Suppression of the D1-receptor denervation supersensitivity in ipsilateral anteromedian striatum by a 6-OHDA injection into the contralateral prefrontal cortex. Animals received either a unilateral 6-OHDA injection into the fields of Forel or both a unilateral injection into the fields of Forel and an injection of 6-OHDA into the contralateral prefrontal cortex and were killed 3 or 7 weeks later. Basal and DAstimulated adenylate cyclase activity in the controls were $92 \pm 8$ and $250 \pm 20 \mathrm{pmol} / \mathrm{min} / \mathrm{mg}$ protein, respectively. DA-sensitive adenylate cyclase activity was determined in triplicates by the difference between the activity obtained in the presence and absence of DA. Data are expressed as percentages of mean values obtained in corresponding control homogenates. Results are the means \pm SEM obtained with groups of 6 rats. ${ }^{* *} p<0.01$ (Student's $t$ test) compared with respective control values.

1985). In addition, D2-related inhibition is observed following previous stimulation of basal adenylate cyclase activity induced by either VIP, forskolin, or sodium chloride (Enjalbert and Bockaert, 1983; Onali et al., 1985; Weiss et al., 1985). The

Table 1. Effects of 6-OHDA injections made unilaterally into the fields of Forel and contralaterally into the prefrontal cortex on DA and NA levels in the striatum and prefrontal cortices

\begin{tabular}{|c|c|c|c|c|}
\hline & \multicolumn{4}{|c|}{$\%$ Control value } \\
\hline & \multicolumn{2}{|c|}{$\begin{array}{l}\text { 6-OHDA into left } \\
\text { fields of Forel }\end{array}$} & \multicolumn{2}{|c|}{$\begin{array}{l}\text { 6-OHDA into left } \\
\text { fields of Forel } \\
+6-O H D A \text { into righ } \\
\text { prefrontal cortex }\end{array}$} \\
\hline & $\overline{\mathrm{DA}}$ & NA & $\overline{\mathrm{DA}}$ & NA \\
\hline \multicolumn{5}{|c|}{ Prefrontal cortex } \\
\hline Left & $11 \pm 3$ & $5 \pm 2$ & $13 \pm 3$ & $3 \pm 2$ \\
\hline Right & $94 \pm 4$ & $94 \pm 4$ & $21 \pm 3$ & $4 \pm 1$ \\
\hline \multicolumn{5}{|c|}{ Anteromedian striatum } \\
\hline Left & $4 \pm 3$ & n.d. & $4 \pm 2$ & n.d. \\
\hline
\end{tabular}

Control values were $0.9 \pm 0.08$ and $2.1 \pm 0.1 \mathrm{ng} / \mathrm{mg}$ protein, respectively, for DA and NA in the prefrontal cortex and $105 \pm 9 \mathrm{ng} / \mathrm{mg}$ protein for DA in the anteromedian striatum. Results are means \pm SEM obtained with groups of at least 5 animals. n.d., not detected. 
absence of exogenous GTP and of these stimulatory agents in our experimental conditions probably explains why the addition of sulpiride, a D2-selective antagonist, did not significantly modify striatal DA-stimulated adenylate cyclase activity (Enjalbert and Bockaert, 1983) in either striatal subdivisions whether tested in control or in lesioned animals.

Difference observed between various striatal areas in the effects of 6-OHD $\Lambda$ injection into the fields of Forel could be related to differential changes in GTP striatal concentration. For example, the selective depletion of GTP in the laterodorsal striatum could inhibit the coupling of D1 receptors with adenylate cyclase and prevent increases in DA-sensitive adenylate cyclase activity. However, the addition of GTP $(1 \mu \mathrm{M})$ did not potentiate stimulation by DA of adenylate cyclase activity either in the laterodorsal or anteromedian striatum, excluding a role of GTP in the effects obtained following 6-OHDA lesion.

\section{Significance of the increase in DA-stimulated adenylate cyclase activity}

As already indicated, a population of "spare D1 receptors" not coupled to adenylate cyclase has been demonstrated in the striatum (Meller et al., 1985; Hess et al., 1987). According to Hess et al. (1987), this population corresponds approximately to $40 \%$ of the total population of D1 receptors present in the striatum. Therefore, the increase in DA-stimulated adenylate cyclase activity seen in the striatal areas examined following DA denervation in some of our experiments could be easily explained by a decrease in the density of "spare D1 receptors," that is, by an increase in the number of $D 1$ receptors coupled to adenylate cyclase. It cannot be excluded, however, that the observed supersensitivity of D1 rcceptors is linked to changes in the efficacy of coupling. In any case, the total number of D1 receptors does not seem to be affected since, as reported by others (Beresford et al., 1988; Savasta et al., 1988), we failed to detect, in similar experimental conditions, a change in striatal ${ }^{3} \mathrm{H}-\mathrm{SCH} 23390$ binding by quantitative autoradiography (data not shown).

\section{Time-related changes in D1-receptor supersensitivity following striatal $D A$ denervation}

We have shown in the present experiments that the amplitude of denervation supersensitivity of D1 receptors in the rat striatum is not homogeneous throughout this structure and that several factors can affect its development.

The time elapsed following the destruction of the nigrostriatal DA pathway seems critical. Indeed, DA-sensitive adenylate activity increased rapidly, reaching maximal levels 3 weeks after the 6-OHDA lesion and then declining at rates depending on the striatal areas examined. For example, the anteromedian and ventromedian parts of the striatum, which receive afferent fibers originating from the prefrontal cortex (Beckstead, 1979; Donoghue and Herkenham, 1986), developed a significant hypersensitivity of D1 receptors as long as 7 weeks following the lesion. This hypersensitivity at 7 weeks postlesion could no longer be observed in the laterodorsal and central parts of the striatum, subdivisions that are not innervated by the prefrontal cortex.

Since no regeneration or sprouting of DA nerve terminals (as indicated by DA levels) occurred in the striatum several weeks after the 6-OHDA destruction of ascending DA fibers, the disappearance of D1 receptor supersensitivity in the laterodorsal striatum at this time was likely due to heterologous regulation of D1 receptors by non-DA fibers. The influence of these non-
DA fibers in the laterodorsal part of the striatum would be very pronounced since a complete reversal of the DI-receptor denervation supersensitivity seen 3 weeks after the lesion was observed when animals were killed 7 weeks after the destruction of the DA neurons. Such a long-term reversal in the effects of lesions of nigrostriatal DA neurons has already been reported in electrophysiological and behavioral studies (Ungerstedt, 1971; Schultz and Ungerstedt, 1978; Marshall, 1979; Staunton et al., 1981). We propose that non-DA systems afferent or intrinsic to the striatum compensate for the deficits induced by the loss of DA innervation. The precise relationships between these compensatory mechanisms and the reversal of D1-receptor denervation supersensitivity remains, however, unknown.

\section{Influence of the cortical DA innervation on the appearance of the striatal D1-receptor denervation supersensitivity}

As mentioned previously, the main difference between those striatal areas in which hypersensitivity of D1 receptors persisted, and those in which it did not, seem to be their anatomical relationship with the prefrontal cortex and, more precisely, as indicated by the WGA-HRP experiments, with the cortical areas receiving Type 1 DA projections from the VTA (Berger et al., 1976; Lindvall et al., 1978; Björklund and Lindvall, 1984) (Fig. 6). A prolonged D1 receptor denervation supersensitivity requires, at least for the anteromedian part of the striatum, the presence of an intact contralateral prefrontocortical DA innervation. The importance of this contralateral cortical DA innervation can easily be understood since, as demonstrated by the WGA-HRP experiments, approximately half of the corticostriatal fibers afferent to the anteromedian striatum originate from neurons located in the contralateral prefrontal cortex. And indeed, it was found that its destruction prevented the occurrence of D1-receptor denervation supersensitivity in the anteromedian striatum not only 7 weeks but also 3 weeks following the ipsilateral destruction of afferent DA fibers (Fig. 7). Interestingly, this lesion of the contralateral prefrontocortical DA innervation also prevented the D1-receptor denervation supersensitivity observed in the laterodorsal striatum 3 weeks following surgery (data not shown). This latter finding suggests that the destruction of the DA innervation of the contralateral prefrontal cortex influences D1-receptor denervation supersensitivity in this striatal subdivision either directly through a minor population of cortical cells innervating the laterodorsal striatum or indirectly through corticocortical connections.

\section{Possible role of corticostriatal glutamatergic fibers on the regulation of striatal D1 receptor denervation supersensitivity}

The present results obtained with the anteromedian striatum are consistent with previously published reports of D1-receptor denervation supersensitivity in the nucleus accumbens following bilateral 6-OHDA injections made into the VTA (Tassin et al., 1982; Reibaud et al., 1984). In these experiments, the bilateral destruction of cortical DA innervation hampered, 6 weeks later, the development of D1-receptor hypersensitivity in the DA-denervated nucleus accumbens. Moreover, when the corticosubcortical pathways were destroyed D1-receptor denervation supersensitivity in the nucleus accumbens was obtained (Reibaud et al., 1984). Taken together, these data suggest that it is the lack of control by the mesocorticoprefrontal DA system of non-DA corticosubcortical neurons (possibly glutamatergic) that is responsible for the absence of D1-receptor denervation 
hypersensitivity in the anatomically connected subcortical structures.

\section{Reactivity of $D A$ receptors to striatal $D A$ denervation in relation to their anatomical localization}

Savasta et al. (1987) have recently shown that D2-receptor denervation supersensitivity, following destruction of the nigrostriatal DA pathway, is not homogencous throughout the striatum. Using quantitative autoradiography of ${ }^{3} \mathrm{H}$-spiroperidol binding, these authors observed D2-receptor hypersensitivity in the lateral but not in the medial part of the striatum. It would seem therefore, that D1 and D2 receptors in these 2 striatal areas react to DA denervation in opposite ways. The mechanisms responsible for the development of striatal D2-receptor denervation supersensitivity seem, however, to be different from those involved with D1 receptors since D2-receptor denervation supersensitivity is not affected by the destruction of the corticostriatal pathways (Paturle et al., 1987).

Interestingly, numerous behavioral studies of the rat have shown that the medial and lateral striatal areas investigated particularly in our study are functionally distinct (Dunnet et al., 1981; Simon, 1981; Dunnet and Iversen, 1982; Divac, 1983). Further, their anatomical connections suggest that they are in contact with the corticolimbic and sensorimotor systems, respectively. It could be argued that the main subdivisions of the striatum are, in fact, related to the presence of "striosomes" and "matrix" (Graybiel and Ragsdale, 1983; Gerfen, 1984). However, even if these subdivisions have important functional significance, the anatomical data provided by Donoghue and Herkenham (1986) indicate that, while prefrontocortical cells project preferentially into striosomes, these prefrontocortical efferent fibers essentially innervate striosomes located in the medial part of the striatum. Similarly, the cortical cells lying in the somatosensory cortex clearly innervate the laterodorsal part of the striatal matrix (Donoghue and Herkenham, 1986). These data are in good agreement with those obtained in our WGA-HRP experiments.

In conclusion, the present study demonstrates that, in addition to the heteroregulation of D1 receptors in the prefrontal cortex by ascending NA fibers (Tassin et al., 1982, 1986) and of D1 receptors in the nucleus accumbens by corticosubcortical neurons (Reibaud et al., 1984), striatal D1 receptors are also subject to heteroregulation by cortical afferent fibers. Since this innervation originates from cells located in the cortical areas receiving DA projections, it can be postulated that such heteroregulations have important functional significance and that their study may provide new information about relationships existing between the different structures innervated by the ascending DA pathways.

\section{References}

Beckstead, R. M. (1979) An autoradiographic examination of corticocortical and subcortical projections of the mediodorsal-projection (prefrontal) cortex in the rat. J. Comp. Neurol. 184: 43-62.

Beresford, I. J. M., A. P. Davenport, D. J. S. Sirinathsinghji, M. D. Hall, R. G. Hill, and J. Hugues (1988) Experimental hemiparkinsonism in the rat following chronic unilateral infusion of $\mathrm{MPP}^{+}$into the nigrostriatal pathway. II. Differential localization of dopamine and cholecystokinin receptors. Neuroscience 27: 129-143.

Berger, B., A. M. Thierry, J. P. Tassin, and M. A. Moyne (1976) Dopaminergic innervation of the rat prefrontal cortex: A fluorescence histochemical study. Brain Res. 106: 133-145.
Björklund, A., and O. I indvall (1984) Dopamine-containing systems in the CNS. In Handbook of Chemical Neuroanatomy, Vol. 2, A. Björklund and T. Hökfelt, eds., pp. 55-122, Elsevier, New York.

Bockaert, J., J. P. Tassin, A. M. Thierry, J. Glowinski, and J. Prémont (1977) Characteristics of dopamine and $\beta$-adrenergic sensitive adenylate cyclases in the frontal cerebral cortex of the rat. Comparative effects of neuroleptics on frontal cortex and striatal dopamine-sensitive adenylate cyclases. Brain Res. 122: 71-86.

Boyson, S. J., P. McGonicle, and P. B. Molinoff (1986) Quantitative autoradiographic localization of the D1 and D2 subtypes of dopamine receptors in rat brain. J. Neurosci. 6: 3177-3188.

Divac, I. (1983) Two levels of functional heterogeneity of the neostriatum. Neuroscience 4: 1151-1155.

Donoghue, J. P., and M. Herkenham (1986) Neostriatal projections from individual cortical fields conform to histochemically distinct striatal compartments in the rat. Brain Res. 365:397-403.

Dunnet, S. B., and S. D. Iversen (1982) Sensorimotor impairments following localized kainic acid and 6-hydroxydopamine lesions of the neostriatum. Brain Res. 248: 121-127.

Dunnet, S. B., A. Björklund, U. Stenevi, and S. D. Iversen (1981) Grafts of embryonic substantia nigra reinnervating the ventrolateral striatum ameliorate sensorimotor impairments and akinesia in rats with 6-OHDA lesions of the nigro-striatal pathway. Brain Res. 229: 209-217.

Enjalbert, A., and J. Bockaert (1983) Pharmacological characterization of the D2-dopamine receptor negatively coupled with adenylate cyclase in rat anterior pituitary. Mol. Pharmacol. 23: 576-584.

Enjalbert, A., F. Sladeczeck, G. Guillon, P. Bertrand, C. Shu, J. Epelbaum, A. Garcia-Sainz, S. Jard, C. Lombard, C. Kordon, and J. Bockaert (1986) Angiotensin II and dopamine modulate both cAMP and inositol phosphate productions in anterior pituitary cells. J. Biol. Chem. 261: 4071-4075.

Ferron, A., A. M. Thierry, C. Le Douarin, and J. Glowinski (1984) Inhibitory influence of the mesocortical dopaminergic system on spontaneous activity or excitatory response induced from the thalamic mediodorsal nucleus in the rat medial prefrontal cortex. Brain Res. 302: 257-265.

Freedman, J. E., and F. F. Weight (1988) Single $\mathrm{K}^{+}$channels activated by $\mathrm{D} 2$ dopamine receptors in acutely dissociated neurons from rat corpus striatum. Proc. Natl. Acad. Sci. USA 85: 3618-3622.

Gauchy, C., J. P. Tassin, J. Glowinski, and A. Chéramy (1976) Isolation and radioenzymatic estimation of picogram quantities of dopamine and norepinephrine in biological samples. J. Neurochem. 26: $471-480$.

Gerfen, C. R. (1984) The neostriatal mosaic: Compartmentalization of cortico-striatal input and striatonigral output systems. Nature 311 : 461-464.

Graybiel, A. M., and C. W. Ragsdale, Jr. (1983) Biochemical anatomy of the striatum. In Chemical Neuroanatomy, P. C. Emson, ed., pp. 427-504, Raven, New York.

Hess, E. J., G. Battaglia, A. Norman, and I. Creese (1987) Differential modification of striatal D1 dopamine receptors and effector moieties by $\mathrm{N}$-ethoxycarbonyl-2-ethoxy-1,2-dihydroquinoline in vivo and in vitro. Mol. Pharmacol. 31: 50-57.

Kebabian, J. W., G. L. Petzold, and P. Greengard (1972) Dopaminesensitive adenylate cyclase in caudate nucleus of rat brain and its similarity to the "dopamine receptor". Proc. Natl. Acad. Sci. USA 69: 2145-2149.

König, S. F. R., and R. A. Klippel (1963) The Rat Brain: A Stereotaxic Atlas of Forebrain and Lower Parts of the Brain Stem, Williams \& Wilkins, Baltimore.

Krettek, J. E., and J. L. Price (1977) The cortical projections of the mediodorsal nucleus adjacent thalamic nuclei in the rat. J. Comp. Neurol. 171: 157-192.

Krueger, B. K., J. Forn, J. R. Walters, R. H. Roth, and P. Greengard (1976) Stimulation by dopamine of adenosine cyclic $3^{\prime}, 5^{\prime}$-monophosphate formation in rat caudate nucleus: Effect of lesions of the nigro-neostriatal pathway. Mol. Pharmacol. 12: 639-648.

Langer, S. Z., C. Pimoule, G. P. Reynolds, and H. Schoemaker (1986) Dopaminergic denervation does not affect $\left({ }^{3} \mathrm{H}\right)-\mathrm{SCH} 23390$ binding in the rat striatum. Br. J. Pharmacol. 87: 161P.

Lavielle, S., J. P. Tassin, A. M. Thierry, G. Blanc, D. Hervé, C. Barthélémy, and J. Glowinski (1979) Blockade by benzodiazepines of selective high increase in dopamine turnover induced by stress in 
mesocortical dopaminergic neurons of the rat. Brain Res. 168: 585594.

Lindvall, O., A. Björklund, and I. Divac (1978) Organization of catecholaminc ncurons projecting to the cortex in the rat. Brain Res. 142: $1-24$.

Marshall, J. F. (1979) Somatosensory inattention after dopaminedepleting intracerebral 6-OHDA injections: Spontaneous recovery and pharmacological control. Brain Res. 177: 311-324.

Meller, E., K. Bohmaker, M. Goldstein, and A. J. Friedhoff (1985) Inactivation of $\mathrm{D} 1$ and $\mathrm{D} 2$ receptors by $\mathrm{N}$-ethoxycarbonyl-2-ethoxy1,2-dihydroquinoline in vivo: Selective protection by neuroleptics. J. Pharmacol. Exp. Ther. 223: 656-662.

Mesulam, M. M. (1978) Tetramethyl benzidine for horseradish peroxidase neurohistochemistry: A non-carcinogenic blue reaction product with superior sensitivity for visualizing neural afferents and efferents. J. Histochem. Cytochem. 26: 106-117.

Mishra, R. K., E. L. Gardner, R. Katzman, and M. H. Makman (1974) Enhanccment of dopamine-stimulated adenylate cyclase activity in rat caudate after lesions in substantia nigra: Evidence for denervation supersensitivity. Proc. Natl. Acad. Sci. USA 71: 3883-3887.

Onali, P. L., M. C. Olianas, and G. L. Gessa (1985) Characterization of dopamine receptors mediating inhibition of adenylate cyclase activity in rat striatum. Mol. Pharmacol. 28: 138-145.

Paturle, L., D. Fage, O. Fournier, P. Vernier, C. Feuerstein, P. Demenge, and B. Scatton (1987) Cortical ablation fails to influence striatal dopamine target cell supersensitivity induced by nigrostriatal denervation in the rat. Brain Res. 402: 383-386.

Prémont, J., M. Perez, G. Blanc, J. P. Tassin, A. M. Thierry, D. Hervé, and J. Bockaert (1979) Adenosine-sensitive adenylate cyclase in rat brain homogenates: Kinetic characteristics, specificity, topographical, subcellular and cellular distribution. Mol. Pharmacol. 16: 790-804.

Reibaud, M., G. Blanc, J. M. Studler, J. Glowinski, and J. P. Tassin (1984) Non-DA prefronto-cortical efferent fibers modulate D1 receptors in the nucleus accumbens. Brain Res. 305: 43-50.

Rodbell, M. (1980) The role for hormone receptors and GTP-regulatory proteins in membrane transduction. Nature 284: 17-22.

Salomon, Y., C. Londos, and M. Rodbell (1974) A highly sensitive adenylate cyclase assay. Anal, Biochem. 58: 541-548.

Savasta, M., A. Dubois, C. Feuerstein, M. Manier, and B. Scatton (1987) Denervation supersensitivity of striatal D2-dopamine receptors is restricted to the ventro- and dorso-lateral regions of the striatum. Neurosci. Lett. 74: 180-186.
Savasta, M., A. Dubois, J. Benavides, and B. Scatton (1988) Different plasticity changes in D1 and D2 receptors in rat striatal subregions following impairment of dopaminergic transmission. Neurosci. Lett. 85: $119-124$.

Schultz, W., and U. Ungerstedt (1978) Short-term increase and longterm reversion of striatal cell activity after degeneration of the nigrostriatal dopamine system. Exp. Brain Res. 33: 159-171.

Simon, H. (1981) Neurones dopaminergiques A10 et système frontal. J. Physiol. (Paris) 77: 81-96.

Staunton, D. A., B. B. Wolfe, P. M. Groves, and P. B. Molinoff (1981) Dopamine receptor changes following destruction of the nigro-striatal pathway: Lack of a relationship to rotational behavior. Brain Res. 211: 315-327.

Tassin, J. P., H. Simon, D. Hervé, G. Blanc, M. Le Moal, J. Glowinski, and J. Bockaert (1982) Non-dopaminergic fibres may regulate dopamine-sensitive adenylate cyclase in the prefrontal cortex and nucleus accumbens. Nature 295: 696-698.

Tassin, J. P., J. M. Studler, D. Hervé, G. Blanc, and J. Glowinski (1986) Contribution of noradrenergic neurons to the regulation of dopaminergic (D1) receptor denervation supersensitivity in rat prefrontal cortex. J. Neurochem. 46: 243-248.

Thierry, A. M., J. P. Tassin, and J. Glowinski (1984) Biochemical and electrophysiological studies of the mesocortical dopamine system. In Monoamine Innervation of Cerebral Cortex, L. Descarries, T. R. Reader, and H. H. Jasper, eds., pp. 233-261, Liss, New York.

Ungerstedt, U. (1971) Postsynaptic supersensitivity after 6-hydroxydopamine induced degeneration of the nigro-striatal dopamine system. Acta Physiol. Scand. Suppl. 367: 69-93.

Von Voigtlander, P. F., S. J. Boukma, and S. Johnson (1973) Dopaminergic denervation supersensitivity and dopamine stimulated adenylate cyclase activity. Neuropharmacology 12: 1081-1086.

Wagner, J., P. Vitali, M. G. Palfreyman, M. Zaika, and S. Huot (1982) Simultaneous determination of 3,4-dihydroxyphenylalanine, 5-hydroxytryptophan, dopamine, 4-hydroxy-3-methoxyphenylalanine, norepinephrine, 3-4-dihydroxyphenylacetic acid, homovanillic acid, serotonin, and 5-hydroxyindolacetic acid in rat cerebrospinal fluid and brain by high performance liquid chromatography with electrochemical detection. J. Neurochem. 38: 1241-1254.

Weiss, S., M. Sebben, J. A. Garcia-Sainz, and J. Bockaert (1985) D2dopamine receptor mediated inhibition of cyclic AMP formation in striatal neurons in primary culture. Mol. Pharmacol. 27: 595-599. 